\title{
Muscle strength, an independent determinant of glycemic control in older adults with long-standing type 2 diabetes: a prospective cohort study
}

Bo Kyung Koo ${ }^{1,2+}$, Seoil Moon ${ }^{3 \dagger}$ and Min Kyong Moon ${ }^{1,2^{*}}$

\begin{abstract}
Background: Although the proportion of older patients with type 2 diabetes mellitus (T2DM) has increased, few studies have reported the factors affecting glucose levels in older patients with long-standing T2DM. This study assessed the determinants of glycemic control in older adults with T2DM of a duration of $\geq 10$ years, including muscle mass, muscle quality, and $\beta$-cell function.

Methods: This was a prospective study of older patients aged $\geq 60$ years with a T2DM duration of $\geq 10$ years. The Homeostatic Model Assessment of Insulin Resistance (HOMA-IR) index, handgrip strength (HGS), and body composition through bioelectrical impedance analysis were assessed. The primary outcome was a composite of: (i) increment of glycated hemoglobin ( $\mathrm{HbA1c}$ ) from the baseline $\geq 0.6 \%$ and (ii) $\mathrm{HbA} 1 \mathrm{c} \geq 9 \%$ at any time point during the follow-up period. To find the predicting determinants of the outcome, we performed the Cox proportional hazard analysis.

Results: Among 100 patients (mean age, 64.0 18.6 years; median duration of diabetes, 20 [interquartile range (IQR), 17-23] years; median HbA1c at baseline, 7.1 [IQR, 6.7-7.4] \%), the primary outcome was observed in 40 (40.0\%) patients during 4.0 (IQR 2.3-5.0) years of follow-up. A Cox proportional hazards model adjusted for age, sex, baseline $\mathrm{HbA1c}$, obesity, duration of DM and anti-diabetic medication at baseline showed that low HGS and insulin resistance at the baseline were independent determinants of the primary outcome (hazard ratio [HR] $=2.23$ [95\% confidence interval (Cl), 1.06-4.72] and 2.39 [95\% Cl, 1.18-4.83], respectively). Sex stratification confirmed that HGS and muscle mass were independent determinants of the primary outcome only in women (HR per quartile, 0.58 [95\% Cl, 0.37 $0.93]$ and 0.46 [95\% Cl, 0.25-0.85], respectively). '.
\end{abstract}

Conclusions: Low HGS and insulin resistance were independent risk factors for aggravated glycemic control among older patients with long standing T2DM.

Keywords: Diabetes mellitus, type 2, Older adult, Sarcopenia, Handgrip strength

*Correspondence: mkmoon@snu.ac.kr

${ }^{\dagger}$ Bo Kyung Koo and Seoil Moon contributed equally to this work.

${ }^{2}$ Division of Endocrinology, Department of Internal Medicine, Seoul National University Boramae Medical Center, Seoul, Republic of Korea Full list of author information is available at the end of the article

\section{Background}

The rate of failure of anti-diabetic agents in patients with long-standing diabetes mellitus (DM) is high; this is because of the associated progressive $\beta$-cell dysfunction in type 2 diabetes mellitus (T2DM) [1-3]. A previous study reported that among patients with a T2DM duration $\geq 10$ years, the proportion of patients who were 
on insulin were above $25 \%$ of the study population, and this proportion increased to about $50 \%$ among patients with a T2DM duration of 20 years [2]. With the increasing life expectancy, the proportion of older patients with diabetes has increased $[4,5]$. Most of these patients have long-standing DM, which results in a high prevalence of diabetic complications and increased mortality risk [6]. Early aggressive glycemic controls [7], medications [3, 7], physical activity [8], and quality of self-care are determinants of glycemic control in T2DM; however, few studies have reported the factors affecting glucose levels in older patients with long-standing DM.

Older patients with DM tend to have coexisting cognitive dysfunction [9], functional disability, emotional lability [10], and other comorbidities, such as cardiovascular diseases (CVD), stroke, or malignancies; these co-existing diseases are more frequent in young patients with DM [6] and are barriers to proper glycemic control $[9,11]$. In addition, economic dependency of the older population makes their management difficult [12]. In Korea, despite the high prevalence of DM in the population $\geq 65$ years old, only about $30 \%$ of them reach the target HbA1c [5].

Aging reduces normal $\beta$-cell function [11], and $\beta$-cell senescence is more prominent in patients with DM compared to non-diabetic individuals [13]. In addition, sarcopenia and increasing fat mass that occur during aging are factors that aggravate glycemic control in older patients [14]. There are few studies elucidating the role of residual $\beta$-cell function and sarcopenia on glycemic control in older patients with long-standing DM. A recent crosssectional study with older patients with DM showed that poor glycemic control was associated with low muscle mass [15]. Therefore, this study sought to identify the determinants of glycemic control in older patients with T2DM of a disease duration $\geq 10$ years, including muscle mass, muscle quality, and $\beta$-cell function.

\section{Methods}

\section{Study subjects}

This was a prospective cohort study. Patients who were at least 60 years old, diagnosed with T2DM at least 10 years ago, and had results of two consecutive oral glucose tolerance tests (OGTTs) performed 3 years apart were eligible for this study. The exclusion criteria were: (1) patients with baseline $\mathrm{HbA} 1 \mathrm{c} \geq 9 \%$, (2) patients receiving insulin for glycemic control, or (3) patients with a history of malignancy or systemic steroid therapy. No specific protocol for the prescription of anti-diabetic medication was used in this study. The routine clinical settings and guidelines were used in managing the patients with DM [16]. For the evaluation of insulin resistance and $\beta$-cell function, the participants underwent OGTT at baseline and 3 years thereafter. The protocol was approved by the Institutional Review Board of the Seoul National University Boramae Medical Center (IRB No. 06-2011-93). Written informed consent was obtained from all the participants.

\section{Study outcomes}

The primary outcome was a composite of (i) increment of HbA1c from the baseline $(\triangle \mathrm{HbA} 1 \mathrm{c}) \geq 0.6 \%$ and (ii) $\mathrm{HbA1c} \geq 9 \%$ at any time point during the follow-up period irrespective of the baseline value. The secondary outcome was a composite of (a) the two primary outcomes and (b) change of medication due to hyperglycemia. For (b), the HbA1c level at the time of medication change was not considered to define an event. The patients were divided into two groups: the aggravation group with the primary outcome and the maintenance group without the primary outcome. Considering that the glycemic targets for older patients range from HbA1c $7.0 \%$ to HbA1c $8.5 \%$ depending on life expectancy, comorbidities, complications and physical status of the patients [17], HbA1c $\geq 9 \%$ was adopted to define aggravation. In addition, change of medication as an addon therapy due to hyperglycemia would be resulted in $0.4 \sim 0.6 \%$ of $\mathrm{HbA} 1 \mathrm{c}$ reduction [18-21], $\triangle \mathrm{HbA} 1 \mathrm{c} \geq 0.6 \%$ was added to the primary outcome.

\section{Metabolic parameters measurement}

During the 75-g OGTT, the plasma glucose and insulin level at 0 and $30 \mathrm{~min}$ were measured to assess insulin resistance and insulin secretion capacity. The insulinogenic index (IGI) was calculated using the following formula from OGTT as an index of $\beta$-cell function: $\left[\Delta\right.$ insulin $(\mathrm{uU} / \mathrm{mL})_{0-30} \mathrm{~min} / \Delta$ glucose $(\mathrm{mg} / \mathrm{dL})_{0-30}$ min] [22]. The Homeostatic Model Assessment for $\beta$-cell $($ HOMA- $\beta$ ) index was calculated using $[20 \times$ fasting glucose $(\mathrm{mmol} / \mathrm{L})] /[$ fasting glucose $(\mathrm{mmol} / \mathrm{L})-3.5]$ [22] The Homeostatic Model Assessment for Insulin Resistance (HOMA-IR) index was calculated using: [fasting glucose $(\mathrm{mmol} / \mathrm{L}) \times$ fasting insulin $(\mathrm{uU} / \mathrm{mL})] / 22.5[22]$; insulin resistance was defined as a HOMA-IR index $\geq 2.5$ [23].

Hypertension (HTN) was defined as a systolic blood pressure $(\mathrm{BP}) \geq 140 \mathrm{mmHg}$, diastolic $\mathrm{BP} \geq 90 \mathrm{mmHg}$, or ongoing treatment with antihypertensive medications. Obesity and abdominal obesity were defined as a body mass index $(\mathrm{BMI}) \geq 25 \mathrm{~kg} / \mathrm{m}^{2}$ [24] and waist circumference $\geq 90$ and $\geq 85 \mathrm{~cm}$ in men and women, respectively [25]. Elevated high-sensitivity C-reactive protein (hs$\mathrm{CRP}$ ) was defined as levels $\geq 1 \mathrm{mg} / \mathrm{L}$ [26]. Renal function was calculated using the modification of diet in renal disease (MDRD) estimated glomerular filtration rate (eGFR) [27]. 
Assessment of muscle and fat mass and hand grip strength Handgrip strength (HGS) was assessed using a digital grip strength dynamometer (TKK 5401; Takei, Tokyo, Japan), as previously reported [28]. Briefly, HGS was measured with the patient standing upright and elbow in full extension. The participants were instructed to squeeze the dynamometer as strongly as possible, for at least three seconds. Low HGS was defined as $<27 \mathrm{~kg}$ in men and $<16 \mathrm{~kg}$ in women, respectively, following the revised guidelines of the European Working Group on Sarcopenia in Older People [29]. To estimate the doseresponse relationship between HGS and the risk of outcome, the quartiles of muscle strength were calculated for each sex, with $\mathrm{Q}_{1}$ and $\mathrm{Q}_{4}$ being the lowest and highest quartiles, respectively.

Bioelectrical impedance analysis was performed using the InBody 330 body composition analyzer (InBody, Seoul, Korea), which measures the muscle and fat mass. Muscle mass and fat mass were expressed as a percentage (muscle/weight [muscle\%] or fat/weight [fat\%]), and their quartiles were calculated for each sex.

\section{Statistical analysis}

All data were analyzed using IBM SPSS Statistics 20.0 for Windows (IBM Inc., Chicago, IL, USA). The demographic and clinical data of the patients with and without glucose deterioration were compared using the MannWhitney test, an independent t-test, and a chi-square test. The Cox proportional hazards model was used to investigate the predicting factors for primary or secondary outcomes after adjustments for sex, age, baseline HbA1c, obesity, and duration of diabetes. The level of statistical significance was set at $P<0.05$.

\section{Results}

\section{Baseline characteristics}

A total of 186 patients were eligible in the study. Among them, 100 patients underwent two consecutive OGTTs and were enrolled in this study (mean age 64.0 \pm 8.6 years; men, 49.0\%). Their duration of diabetes was 20 years (interquartile range [IQR], 17-23 years). The baseline median HbA1c and BMI were 7.1\% (IQR, 6.7-7.4\%) and $24.2 \mathrm{~kg} / \mathrm{m}^{2}$ (IQR, $22.1-26.6 \mathrm{~kg} / \mathrm{m}^{2}$ ), respectively. Metformin, dipeptidyl peptidase-IV (DPP4) inhibitors, and sulfonylurea (SU) were used in 91.0, 64.0, and $68.0 \%$ of the patients at baseline (Table 1).

The median follow-up duration was 4.0 (IQR 2.35.0) years. The primary and secondary outcomes were observed in 40 and 78 patients, respectively during the follow-up period. Each outcome was detected in $38(38.0 \%), 14(14.0 \%)$, and $71(71.0 \%)$ patients for $\Delta \mathrm{HbA} 1 \mathrm{c} \geq 0.6 \%, \mathrm{HbA} 1 \mathrm{c} \geq 9 \%$, and medication change, respectively. The median $\mathrm{HbA1c}$ at the development of each outcome was $7.85,9.45$, and $8.00 \%$, respectively (Supplementary Table S1).

There was no difference in age, duration of diabetes, and baseline $\mathrm{HbA} 1 \mathrm{c}$ between the aggravation and maintenance groups (Table 1). BMI, C-peptide, HOMA-IR index, IGI, HOMA $\beta$-cell index, low-density lipoprotein cholesterol, high-density lipoprotein cholesterol, triglyceride, aspartate aminotransferase, alanine aminotransferase, alanine aminotransferase, and GFR were not significantly different between the two groups (Table 1 ). Among the anti-diabetic medication, thiazolidinedione (TZD) was used more in the maintenance group than in the aggravation group ( $18.3 \%$ vs. $2.5 \%, P=0.017$; Table 1$)$. SU and DPP4 inhibitors were used more in the aggravation group than in the maintenance group; the difference was not significant $(P=0.096$ and 0.061 , respectively; Table 1).

Comparing the subjects with and without secondary outcome, there were no differences in age, duration of diabetes, or baseline HbA1c between both groups (Supplementary Table S2). The HOMA-IR index was significantly higher in those with secondary outcome (2.56 [IQR, 2.02-4.01] vs. 2.12 [IQR, 1.66-3.04]; $P=0.038$ ); however, there was no difference in IGI and HOMA $\beta$-cell index between the two groups (Supplementary Table S2). TZD was used less in the patients with secondary outcome than in those without $(9.0 \%$ vs. $22.7 \%$; $P=0.080$; Supplementary Table S2).

\section{Determinants of the primary and secondary outcomes}

A Cox proportional hazards analysis was performed to investigate the determinants of the primary and secondary outcomes (Table 2). Among the various factors, low HGS increased the risk of the primary outcome (unadjusted hazard ratio [HR], 2.274; 95\% confidence interval $[C I], 1.132-4.567 ; P=0.021)$ significantly, whose statistical significance was maintained even after adjustment for age, sex, baseline HbA1c, obesity, duration of DM, and anti-diabetic medication at baseline (HR, 2.234; 95\% CI, 1.058-4.718 $P=0.035$; Model 2 in Table 2; Fig. 1A). The baseline HOMA-IR index $\geq 2.5$ also increased the risk of the primary outcome, which further increased after adjustment (Model 2; HR, 2.386; 95\% CI, 1.178-4.834; $P=0.016)$. IGI, HOMA $\beta$-cell index, muscle mass/body weight (BW), fat mass/BW, and obesity at the baseline did not significantly affect the primary outcome (Table 2).

For the secondary outcome, only a HOMA-IR index $\geq 2.5$ at the baseline increased the risk in the fully adjusted model (HR, 1.705; 95\% CI, 1.048-2.775; $P=0.032$ ). There was no significant association between low HGS and secondary outcome (Table 2, Fig. 1B). 


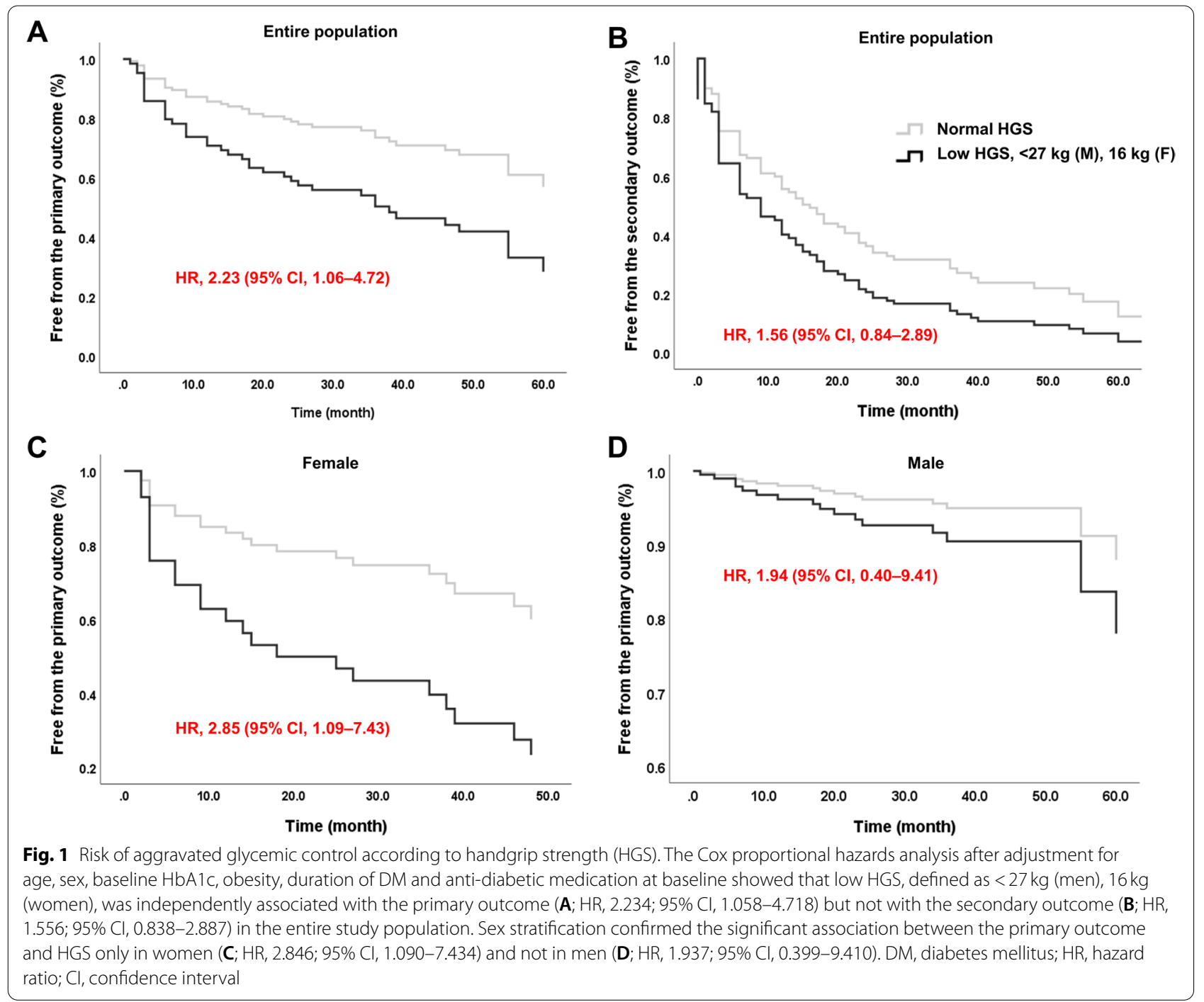

Subsequently, the sex-stratified Cox proportional hazard model was analyzed. In women, there was association of low HGS and HOMA-IR index $\geq 2.5$ with an increased risk of the primary outcome, even after adjustment for age, sex, baseline HbA1c, obesity, duration of DM and anti-diabetic medication at baseline (HR, 2.846; 95\% CI, 1.090-7.434 and HR, 3.810; 95\% CI, 1.307-11.100, respectively; Supplementary Table S3; Fig. 1C). As HGS increased by one quartile, the risk of the primary outcome decreased by $42 \%$ (HR, 0.584; 95\% CI, 0.367-0.929; $P=0.023$; Supplementary Fig. S1A). In addition, both muscle mass/BW and fat mass/BW were significant determinants of the primary outcome (Supplementary Table S3). Muscle mass/BW decreased the risk by $54 \%$ in every quartile (HR, 0.458 ; 95\% CI, $0.249-0.850)$. In contrast, fat mass/BW increased the risk of primary outcome by about two times in every quartile (HR, 1.970; 95\% CI, 1.058-3.667; Supplementary Table S3). The secondary outcome was also significantly associated with a low HGS and HOMA-IR index $\geq 2.5$ in women (HR, 2.298; 95\% CI, 1.002-5.374 and HR, 2.264; 95\% CI, 1.044-4.910, respectively).

In men, low HGS and HOMA-IR index $\geq 2.5$ increased the risk of the primary outcome (HR, 1.937; 95\% CI, 0.399-9.410 and HR 2.155; 95\% CI, 0.748-6.205, respectively; Fig. 1D); however, none of them were significant (Supplementary Table S3). A dose-response relationship between HGS and the risk of the primary outcome was not found in men (Supplementary Fig. S1B).

Low HGS was the most important factor for the primary and secondary outcomes. An additional analysis was conducted with each composite outcome for aggravation of glucose levels according to low HGS. Low HGS significantly increased the risk of two composite outcomes after adjustment for age, sex, and baseline HbA1c for $\Delta \mathrm{HbA} 1 \mathrm{c} \geq 0.6 \%(\mathrm{HR}, 2.793$; 95\% CI, 1.334-5.847; 
$P=0.006)$ and for $\mathrm{HbA} 1 \mathrm{c} \geq 9 \%(\mathrm{HR}, 3.313$; 95\% CI, 1.059-10.361; $P=0.040)$, but not medication change (HR, 1.707; 95\% CI, 0.912-3.193; $P=0.094$ ). Even after additional adjustment for obesity, duration of diabetes and anti-diabetic medication at baseline, low HGS significantly increased the risk of $\Delta \mathrm{HbA} 1 \mathrm{c} \geq 0.6 \%$ (HR, 2.467; 95\% CI, 1.149-5.300; $P=0.021$; Supplementary Table S4).

\section{Discussion}

This study identified the determinants of glycemic control in older patients with T2DM of a duration $\geq 10$ years. Low HGS and insulin resistance were independent risk factors for aggravated glycemic control. Low HGS was associated with a 2.5 times higher risk of the primary outcome in women, which was more prominent compared to that in men. In addition, in women, the risk of aggravated glycemic control had a significant negative and positive correlation with fat mass and muscle mass, respectively. The surrogate markers for $\beta$-cell function did not affect glycemic control, regardless of sex.

Sarcopenia is a progressive and generalized skeletal muscle disorder characterized by low muscle strength, low muscle quantity/quality, and low physical performance [29]. Aging reduces all these sarcopenic indices, and T2DM worsens sarcopenia in older patients [30]. Previous cross-sectional studies showed that poor glycemic control was associated with poor muscle quality [31] and low muscle mass [15] in older patients with T2DM. This prospective study is in line with their findings as sarcopenia was an independent risk factor for aggravated glycemic control $[15,31]$.

HGS is a method for measuring muscle strength when diagnosing sarcopenia [32]. HGS is a risk indicator for T2DM in the general population [33]. A prospective cohort study performed over 10years ago confirmed that a greater HGS prevents T2DM development in persons without diabetes [34]. This study adds evidence of the role of muscle quality on the deterioration of glucose metabolism among older patients with long-standing T2DM. Resistance training significantly improves glycemic control and muscle strength in older patients with T2DM [35]. Improving muscle quality and mass reduces weight gain, abdominal adiposity, insulin resistance, and chronic inflammation, which in turn reduces insulin resistance [36].

Interestingly, the effect of muscle mass and/or muscle power on aggravated glycemic control was higher in women than in men in this study. Furthermore, in women, there was a significant association between poor glycemic control and body composition, which was not found in men. A previous nationwide Korean survey showed a sex disparity in the risk factors for DM [37, 38]; abdominal obesity was associated with a 3 times higher risk of DM in women, which was not found in men [38]; this was consistent with a previous study carried out in a different population [39]. In contrast, the association between genetic factor and DM was more prominent in men than in women [38]. Although the reason for the differences in the association between body fat and DM between men and women is unknown, the prevalence of obesity increases in women who have a lower economic status; this was opposite in men [40]. Low economic status is a well-known risk factor for DM [40], which might partly explain the difference in the association between obesity and DM between the men and women. In addition, women have less muscle mass than men at any given age even after correction for height and weight [41]. This may explain more important role of muscle in metabolic health in women compared to that in men. Recently, a community-based cohort study also reported the deterioration of muscle function as well as reduction of muscle mass in diabetic patients was more prominent in women compared to men [42]; however, there have been conflicting data in the sex-difference in the association between sarcopenia and DM [43-45].

With aging, proliferation of $\beta$-cells reduce and apoptosis of $\beta$-cells increase; this gradually deteriorates pancreatic $\beta$-cell function [46]. However, in this study, there was no significant association between the primary and secondary outcomes and the surrogate markers of $\beta$-cell function. These findings might suggest that $\beta$-cell dysfunction has already been significantly reduced in older patients with long-standing diabetes, and insulin resistance worsens glycemic control than $\beta$-cell dysfunction. $\beta$-cell dysfunction is more common in patients with early-onset diabetes than in those with older age-onset diabetes [14]. In the older population, sarcopenia is the most significant factor for the development of glucose intolerance [14].

Our study had several limitations. First, the sample size was small. This may explain the absence of significant findings among the men after stratification: fewer men, when compared to women, had a low HGS. Second, HGS was not measured serially; therefore, it was not possible to determine the effect of the change of HGS on glycemic control. In addition, hyperglycemia itself results in impaired muscle function [31]; furthermore, improvement of glucose control increases muscle mass and function [47]. It might be difficult to exclude the effect of hyperglycemia at baseline on the association between muscle strength and hyperglycemia event during followup period. Last, genetic information that could help in excluding monogenic DM was unavailable; this may have affected the glycemic control [48]. However, using a prospective cohort of T2DM in a real-life clinical setting showed that muscle power and/or muscle mass played an 
important role in maintaining good glycemic control in older patients with long-standing T2DM.

\section{Conclusions}

HGS is an important determinant in glycemic control in older patients with long-standing T2DM. Considering that an increase in muscle power and muscle mass can be achieved by resistance training in older patients even in the presence of CVD [49] or respiratory dysfunction [50], this study might provide a solid evidence for the importance of resistance training in older patients with T2DM.

\section{Supplementary Information}

The online version contains supplementary material available at https://doi. org/10.1186/s12877-021-02629-5.

Additional file 1: Table S1. HbA1c level at the time point of each outcome. Table S2. Baseline clinical characteristics according to the secondary outcome. Table S3. Determinants of primary and secondary outcome in each sex. Table S4. Cox proportional hazards analysis for aggravation of glucose level according to low handgrip strength. Fig. S1 Cox proportional hazards model with adjustment for age, baseline HbA1c, obesity and duration of DM

\section{Acknowledgments}

Not applicable.

\section{Authors' contributions}

B.K.K., and M.K.M. contributed to the study design. And all authors of this study, B.K.K., S.M., and M.K.M. conducted the acquisition, analysis and interpretation of data, drafting the manuscript and revision.

\section{Funding}

This work was supported by a public healthcare research grant-in-aid from the Seoul Metropolitan Government Seoul National University Boramae Medical Center (04-2019-1) and the Handok Inc., Seoul, Republic of Korea. The funders had no role in study design, data collection and analysis, decision to publish, or preparation of the manuscript.

\section{Availability of data and materials}

The datasets used and analysed during the current study are available from the corresponding author on reasonable request.

\section{Declarations}

\section{Ethics approval and consent to participate}

This study was approved by the Institutional Review Board of the Seoul National University Boramae Medical Center (IRB No. 06-2011-93). Written informed consent was obtained from all the participants. All methods were performed in accordance with the relevant guidelines and regulations.

\section{Consent for publication}

Not applicable.

\section{Competing interests}

The authors have no competing interests.

\section{Author details}

${ }^{1}$ Department of Internal Medicine, Seoul National University College of Medicine, Seoul, Republic of Korea. ${ }^{2}$ Division of Endocrinology, Department of Internal Medicine, Seoul National University Boramae Medical Center, Seoul, Republic of Korea. ${ }^{3}$ Department of Internal Medicine, Seoul National University Hospital, Seoul, Republic of Korea.
Received: 27 July 2021 Accepted: 9 November 2021

Published online: 07 December 2021

\section{References}

1. Bagust A, Beale S. Deteriorating beta-cell function in type 2 diabetes: a long-term model. QJM. 2003;96(4):281-8 https://doi.org/10.1093/qjmed/ hcg040.

2. Hayashino Y, Izumi K, Okamura S, Nishimura R, Origasa H, Tajima N, et al. Duration of diabetes and types of diabetes therapy in Japanese patients with type 2 diabetes: the Japan diabetes complication and its prevention prospective study 3 (JDCP study 3). J Diabetes Investig. 2017;8(2):243-9 https://doi.org/10.1111/jdi.12550.

3. Kahn SE, Haffner SM, Heise MA, Herman WH, Holman RR, Jones NP, et al. Glycemic durability of rosiglitazone, metformin, or glyburide monotherapy. N Engl J Med. 2006;355(23):2427-43 https://doi.org/10.1056/NEJMo a066224.

4. Fang M, Echouffo-Tcheugui JB, Selvin E. Clinical and public health implications of 2019 Endocrine Society guidelines for diagnosis of diabetes in older adults. Diabetes Care. 2020;43(7):1456-61 https://doi.org/10.2337/ dc19-2467.

5. Jung CH, Son JW, Kang S, Kim WJ, Kim HS, Kim HS, et al. Diabetes fact sheets in Korea, 2020: an appraisal of current status. Diabetes Metab J. 2021;45(1):1-10 https://doi.org/10.4093/dmj.2020.0254.

6. Huang ES, Laiteerapong N, Liu JY, John PM, Moffet HH, Karter AJ. Rates of complications and mortality in older patients with diabetes mellitus: the diabetes and aging study. JAMA Intern Med. 2014;174(2):251-8 https:// doi.org/10.1001/jamainternmed.2013.12956.

7. Del Prato S, Foley JE, Kothny W, Kozlovski P, Stumvoll M, Paldanius PM, et al. Study to determine the durability of glycaemic control with early treatment with a vildagliptin-metformin combination regimen vs. standard-of-care metformin monotherapy-the VERIFY trial: a randomized double-blind trial. Diabet Med. 2014;31(10):1178-84 https://doi.org/10. 1111/dme.12508.

8. Mamo Y, Bekele F, Nigussie T, Zewudie A. Determinants of poor glycemic control among adult patients with type 2 diabetes mellitus in Jimma University medical center, Jimma zone, south West Ethiopia: a case control study. BMC Endocr Disord. 2019;19(1):91 https://doi.org/10.1186/ s12902-019-0421-0.

9. Kim YG, Park DG, Moon SY, Jeon JY, Kim HJ, Kim DJ, et al. Hypoglycemia and dementia risk in older patients with type 2 diabetes mellitus: a propensity-score matched analysis of a population-based cohort study. Diabetes Metab J. 2020;44(1):125-33 https://doi.org/10.4093/dmj.2018. 0260 .

10. Dziedzic B, Sienkiewicz Z, Lenczuk-Gruba A, Kobos E, Fidecki W, Wysokiski M. Prevalence of Depressive Symptoms in the Elderly Population Diagnosed with Type 2 Diabetes Mellitus. Int J Environ Res Public Health. 2020;17(10). https://doi.org/10.3390/ijerph17103553.

11. Lee PG, Halter JB. The pathophysiology of hyperglycemia in older adults: clinical considerations. Diabetes Care. 2017;40(4):444-52 https://doi.org/ 10.2337/dc16-1732.

12. American DA. Economic costs of diabetes in the U.S. in 2007. Diabetes Care. 2008;31(3):596-615 https://doi.org/10.2337/dc08-9017.

13. Aguayo-Mazzucato C, Andle J, Lee TB Jr, Midha A, Talemal L, Chipashvili V, et al. Acceleration of beta cell aging determines diabetes and Senolysis improves disease outcomes. Cell Metab. 2019;30(1):129-42 e4 https://doi. org/10.1016/j.cmet.2019.05.006.

14. Koo BK, Roh E, Yang YS, Moon MK. Difference between old and young adults in contribution of beta-cell function and sarcopenia in developing diabetes mellitus. J Diabetes Investig. 2016;7(2):233-40 https://doi.org/10 1111/jdi.12392.

15. Sugimoto K, Tabara Y, Ikegami H, Takata Y, Kamide K, Ikezoe T, et al. Hyperglycemia in non-obese patients with type 2 diabetes is associated with low muscle mass: the multicenter study for clarifying evidence for sarcopenia in patients with diabetes mellitus. J Diabetes Investig. 2019;10(6):1471-9 https://doi.org/10.1111/jdi.13070.

16. Kim MK, Ko SH, Kim BY, Kang ES, Noh J, Kim SK, et al. 2019 clinical practice guidelines for type 2 diabetes mellitus in Korea. Diabetes Metab J. 2019;43(4):398-406 https://doi.org/10.4093/dmj.2019.0137. 
17. American DA. 12. Older adults: standards of medical Care in Diabetes-2021. Diabetes Care. 2021;44(Suppl 1):S168-S79 https://doi.org/10. 2337/dc21-S012.

18. Wu D, Li L, Liu C. Efficacy and safety of dipeptidyl peptidase-4 inhibitors and metformin as initial combination therapy and as monotherapy in patients with type 2 diabetes mellitus: a meta-analysis. Diabetes Obes Metab. 2014;16(1):30-7 https://doi.org/10.1111/dom.12174.

19. Wang B, Sun Y, Sang Y, Liu X, Liang J. Comparison of dipeptidyl peptidase-4 inhibitors and pioglitazone combination therapy versus pioglitazone monotherapy in type 2 diabetes: a system review and metaanalysis. Medicine (Baltimore). 2018;97(46):e12633 https://doi.org/10. 1097/MD.0000000000012633.

20. Cho YK, Kang YM, Lee SE, Lee J, Park JY, Lee WJ, et al. Efficacy and safety of combination therapy with SGLT2 and DPP4 inhibitors in the treatment of type 2 diabetes: a systematic review and meta-analysis. Diabetes Metab. 2018:44(5):393-401 https://doi.org/10.1016/j.diabet.2018.01.011.

21. Wang N, Yang T, Li J, Zhang X. Dipeptidyl peptidase-4 inhibitors as add-on therapy to insulin in patients with type 2 diabetes mellitus: a metaanalysis of randomized controlled trials. Diabetes Metab Syndr Obes. 2019;12:1513-26 https://doi.org/10.2147/DMSO.S202024.

22. Singh B, Saxena A. Surrogate markers of insulin resistance: a review. World J Diabetes. 2010;1(2):36-47 https://doi.org/10.4239/wjd.v1.i2.36.

23. Kuk JL, Ardern Cl. Are metabolically normal but obese individuals at lower risk for all-cause mortality? Diabetes Care. 2009;32(12):2297-9 https://doi. org/10.2337/dc09-0574.

24. Pacific WHOROftW. The Asia-Pacific perspective : redefining obesity and its treatment: Australia : health communications Australia; 2000

25. Nam GE, Kim YH, Han K, Jung JH, Rhee EJ, Lee SS, et al. Obesity fact sheet in Korea, 2019: prevalence of obesity and abdominal obesity from 2009 to 2018 and social factors. J Obes Metab Syndr. 2020;29(2):124-32 https:// doi.org/10.7570/jomes20058.

26. Ridker PM, Wilson PW, Grundy SM. Should C-reactive protein be added to metabolic syndrome and to assessment of global cardiovascular risk? Circulation. 2004;109(23):2818-25 https://doi.org/10.1161/01.CIR.00001 32467.45278 .59 .

27. Levey AS, Coresh J, Greene T, Stevens LA, Zhang YL, Hendriksen S, et al. Using standardized serum creatinine values in the modification of diet in renal disease study equation for estimating glomerular filtration rate. Ann Intern Med. 2006;145(4):247-54.

28. Koo BK. The differential association between muscle strength and diabetes mellitus according to the presence or absence of obesity. J Obes Metab Syndr. 2019;28(1):46-52 https://doi.org/10.7570/jomes.2019.28.1 46.

29. Cruz-Jentoft AJ, Bahat G, Bauer J, Boirie Y, Bruyere O, Cederholm T, et al. Sarcopenia: revised European consensus on definition and diagnosis. Age Ageing. 2019;48(1):16-31 https://doi.org/10.1093/ageing/afy169.

30. Park SW, Goodpaster BH, Strotmeyer ES, Kuller LH, Broudeau R, Kammerer $C$, et al. Accelerated loss of skeletal muscle strength in older adults with type 2 diabetes: the health, aging, and body composition study. Diabetes Care. 2007;30(6):1507-12 https://doi.org/10.2337/dc06-2537.

31. Yoon JW, Ha YC, Kim KM, Moon JH, Choi SH, Lim S, et al. Hyperglycemia is associated with impaired muscle quality in older men with diabetes: the Korean longitudinal study on health and aging. Diabetes Metab J. 2016;40(2):140-6 https://doi.org/10.4093/dmj.2016.40.2.140.

32. Cruz-Jentoft AJ, Sayer AA. Sarcopenia. Lancet. 2019;393(10191):2636-46 https://doi.org/10.1016/s0140-6736(19)31138-9.

33. Kunutsor SK, Isiozor NM, Khan H, Laukkanen JA. Handgrip strength-a risk indicator for type 2 diabetes: systematic review and meta-analysis of observational cohort studies. Diabetes Metab Res Rev. 2021;37(2):e3365 https://doi.org/10.1002/dmrr.3365.

34. Wander PL, Boyko EJ, Leonetti DL, McNeely MJ, Kahn SE, Fujimoto WY. Greater hand-grip strength predicts a lower risk of developing type 2 diabetes over 10 years in leaner Japanese Americans. Diabetes Res Clin Pract. 2011;92(2):261-4 https://doi.org/10.1016/j.diabres.2011.01.007.

35. Lee J, Kim D, Kim C. Resistance training for glycemic control, muscular strength, and lean body mass in old type 2 diabetic patients: a Meta-analysis. Diabetes Ther. 2017;8(3):459-73 https://doi.org/10.1007/ s13300-017-0258-3.

36. Artero EG. Lee D-c, Lavie CJ, España-Romero V, sui X, church TS, et al. effects of muscular strength on cardiovascular risk factors and prognosis. Journal of Cardiopulmonary Rehabilitation and Prevention. 2012;32(6):351-8 https://doi.org/10.1097/HCR.0b013e3182642688.

37. Koo BK, Moon MK. Are we in the same risk of diabetes mellitus? Genderand age-specific epidemiology of diabetes in 2001 to 2014 in the Korean population. Diabetes Metab J. 2016;40(3):175-81 https://doi.org/10.4093/ dmj.2016.40.3.175.

38. Koo BK, Kim SW, Yi KH, Park KS, Moon MK. Changing relative contribution of abdominal obesity and a family history of diabetes on prevalence of diabetes mellitus in Korean men and women aged 30-49 years from 2001 to 2010. J Diabetes. 2015;7(4):465-72 https://doi.org/10.1111/1753-0407. 12202.

39. Fasanmade OA, Okubadejo NU. Magnitude and gender distribution of obesity and abdominal adiposity in Nigerians with type 2 diabetes mellitus. Niger J Clin Pract. 2007;10(1):52-7.

40. Koo BK, Kim SW, Yi KH, Moon MK. Low economic status is identified as an emerging risk factor for diabetes mellitus in korean men aged 30 to 59 years in korean national health and nutrition examination survey 2008 to 2010. Diabetes Metab J. 2015;39(2):137-46 https://doi.org/10.4093/dmj. 2015.39.2.137.

41. Mitchell WK, Williams J, Atherton P, Larvin M, Lund J, Narici M. Sarcopenia, dynapenia, and the impact of advancing age on human skeletal muscle size and strength; a quantitative review. Front Physiol. 2012;3:260 https:// doi.org/10.3389/fphys.2012.00260.

42. Kang S, Oh TJ, Cho BL, Park YS, Roh E, Kim HJ, et al. Sex differences in sarcopenia and frailty among community-dwelling Korean older adults with diabetes: the Korean frailty and aging cohort study. J Diabetes Investig. 2021;12(2):155-64 https://doi.org/10.1111/jdi.13348.

43. de Freitas MM, de Oliveira VLP, Grassi T, Valduga K, Miller MEP, Schuchmann RA, et al. Difference in sarcopenia prevalence and associated factors according to 2010 and 2018 European consensus (EWGSOP) in elderly patients with type 2 diabetes mellitus. Exp Gerontol. 2020;132:110835 https://doi.org/10.1016/j.exger.2020.110835.

44. Fukuoka Y, Narita T, Fujita H, Morii T, Sato T, Sassa MH, et al. Importance of physical evaluation using skeletal muscle mass index and body fat percentage to prevent sarcopenia in elderly Japanese diabetes patients. J Diabetes Investig. 2019;10(2):322-30 https://doi.org/10.1111/jdi.12908.

45. Chen F, Xu S, Wang Y, Chen F, Cao L, Liu T, et al. Risk factors for sarcopenia in the elderly with type 2 diabetes mellitus and the effect of metformin. J Diabetes Res. 2020;2020:3950404 https://doi.org/10.1155/2020/3950404.

46. Gunasekaran U, Gannon M. Type 2 diabetes and the aging pancreatic beta cell. Aging (Albany NY). 2011;3(6):565-75. https://doi.org/10.18632/ aging. 100350.

47. Sugimoto K, Ikegami H, Takata Y, Katsuya T, Fukuda M, Akasaka H, et al. Glycemic control and insulin improve muscle mass and gait speed in type 2 diabetes: the MUSCLES-DM study. J Am Med Dir Assoc. 2021;22(4):834-8 e1 https://doi.org/10.1016/j.jamda.2020.11.003.

48. Yang YS, Kwak SH, Park KS. Update on monogenic diabetes in Korea. Diabetes Metab J. 2020;44(5):627-39 https://doi.org/10.4093/dmj.2020. 0214.

49. Yamamoto S, Hotta K, Ota E, Mori R, Matsunaga A. Effects of resistance training on muscle strength, exercise capacity, and mobility in middleaged and elderly patients with coronary artery disease: a meta-analysis. J Cardiol. 2016;68(2):125-34 https://doi.org/10.1016/j.jjcc.2015.09.005.

50. Liao W. Chen JW, Chen X, Lin L, Yan Hy, Zhou Yq, et al. impact of resistance training in subjects with COPD: a systematic review and Meta-analysis. Respir Care. 2015;60(8):1130-45 https://doi.org/10.4187/respcare.03598.

\section{Publisher's Note}

Springer Nature remains neutral with regard to jurisdictional claims in published maps and institutional affiliations. 